\title{
Aneurysmal Surgery in the Presence of Angiographic Vasospasm: An Outcome Assessment
}

\author{
Nancy McLaughlin, Michel W. Bojanowski
}

\begin{abstract}
Background and Purpose: The timing of aneurysmal surgery for patients presenting within the period at risk for vasospasm (VS) is controversial. The goal of this study is to review our experience of surgically treated patients in the presence of angiographic VS. Materials and Methods: From 1990-2004, 894 consecutive patients presented with an aneurysmal subarachnoid hemorrhage $(\mathrm{SAH})$ and were treated with a policy of early surgery. We retrospectively analyzed the patients that had pre-operative angiographic VS. In this study, symptomatic VS was diagnosed when a decreased level of consciousness and/or focal deficit occurred after SAH in the presence of angiographic VS without confounding factors. Functional outcome was assessed three months after SAH using the Glasgow Outcome Scale. Results: Of the 40 patients studied, 62.5\% were in good clinical grade Hunt \& Hess (H\&H 1-2) on admission; 25\%, intermediate grade $(\mathrm{H} \& \mathrm{H} 3) ; 12.5 \%$, poor grade $(\mathrm{H} \& \mathrm{H} 4-5)$. Surgery was performed 24 hours or less after initial angiography in $87.5 \%$ of patients and less than 48 hours in $97.5 \%$. Pre-operative symptomatic VS was diagnosed in $25 \%$. Postoperatively, angiographic VS was documented in $87.2 \%$. Of the $30 \%$ of patients that presented post-operative symptomatic VS, $66.7 \%$ also demonstrated pre-operative symptomatic VS. The functional outcome was favorable in $92.5 \%$ of the studied patients. Two deaths occurred in patients presenting pre-operative early radiological and symptomatic VS. Conclusion: Aneurysmal surgery, especially between 3-12 days following SAH, in the presence of asymptomatic pre-operative angiographic VS can be associated with a good outcome. Early surgery is not contra-indicated and might enable optimal treatment of VS.
\end{abstract}

RÉSUMÉ: Chirurgie anévrismale en présence de vasospasme angiographique: Analyse du pronostic. Contexte et objectif: Chez les patients qui consultent pour une hémorragie sous-arachnoïdienne (HSA) due à un anévrisme pendant la période à risque de vasospasme (VS), le moment de la ligature de l'anévrisme demeure controversé. Le but de cette étude est de réviser notre expérience chez des patients traités chirurgicalement en présence de VS angiographique. Matériel et Méthode: De 1990 à 2004, 894 patients consécutifs ont été admis pour une HSA due à un anévrisme et ont été traité par une chirurgie précoce. Nous avons analysé de façon rétrospective les patients présentant du VS angiographique pré-opératoire. Dans cette étude, un diagnostic de VS symptomatique était posé en présence d'une altération de la conscience ou d'un déficit focal survenant après une HSA en présence de VS angiographique et en l'absence de facteurs confondants. Le pronostic fonctionnel fut évalué selon l'échelle de Glasgow (GOS) 3 mois suivant l'HSA. Résultats: Parmi les 40 patients étudiés, 62,5\% étaient en bon grade clinique de Hunt\&Hess (H\&H 1-2) à 1'admission; 25\% en grade intermédiaire (H\&H 3); 12,5\% en mauvais grade (H\&H4-5).La chirurgie était réalisée 24 heures ou moins après l'angiographie initiale chez 87,5\% des patients et 48 heures ou moins chez 97,5\% des patients.Un VS symptomatique pré-opératoire fut diagnostiqué dans $25 \%$ des cas. En post-opératoire, un VS angiographique fut documenté dans $87,2 \%$ des cas. Parmi les $30 \%$ qui présentaient un vasospasme symptomatique post-opératoire, $66,7 \%$ avaient également présenté un VS symptomatique avant la chirurgie. Le pronostic fonctionnel était favorable chez $92,5 \%$ des patients étudiés. Deux décès sont survenus chez des patients qui présentaient un VS radiologique et symptomatique précoce. Conclusion: La ligature d'un anévrisme rompu, particulièrement entre le $3 \mathrm{e}$ et 12e jours suivant une HSA, en présence de vasospasme angiographique asymptomatique pré-opératoire, peut être associé à un pronostic favorable. La chirurgie précoce n'est pas contre-indiquée et pourrait favoriser un traitement optimal du VS.

Can. J. Neurol. Sci. 2006; 33: 181-188

The timing of ruptured aneurysm surgery has been a controversial subject in neurosurgery. Several studies have demonstrated that early surgical treatment after aneurysmal subarachnoid hemorrhage (SAH) is technically feasible $e^{1,2}$ reduces the risk of rebleeding ${ }^{1,2}$ and appears to be associated with improved outcome in particular for patients in good clinical condition on admission.,3-5 Some patients, however, delay seeking medical attention, are initially misdiagnosed, or present after a second hemorrhage, and in these patients diagnosis of $\mathrm{SAH}$ can come at a time when cerebral vasospasm (VS) is already present.
Some authors expressed their opinion to refrain from operating cerebral aneurysms during the period at risk for VS regardless of the presence or absence of angiographic VS and

From the Division of Neurosurgery, Department of Surgery, Centre Hospitalier de l'Université de Montréal - Hôpital Notre-Dame, Montreal, Quebec, Canada. Received August 31, 2005. AcCePted in Final form February 17, 2006. Reprint requests to: Michel W. Bojanowski, Division of Neurosurgery, Department of Surgery, CHUM-Hôpital Notre-Dame, 1560 Sherbrooke Est, Montreal, Quebec, H2L 4M1, Canada. 
others have reported an increased frequency of delayed cerebral ischemia and poor outcome in patients undergoing aneurysm clipping during this period..$^{2,4,6-9}$ On the other hand, it has also been argued that immediate aneurysm repair even in the presence of VS is warranted in order to prevent aneurysm rebleeding and to allow for optimal vasospasm treatment, including induced hypertension. ${ }^{3}$

To help inform this controversy, we reviewed our experience with a large series of patients who underwent early surgical aneurysm repair in the presence of angiographic VS.

\section{Material AND Methods}

\section{Patient population}

From 1990 to 2004, 894 consecutive patients were surgically treated for an aneurysmal SAH. During this period, patients with aneurysmal SAH and angiographic VS who underwent surgical treatment at the Centre Hospitalier de l'Université de Montréal were collected for retrospective study. SAH was diagnosed by computed tomography (CT) scan or lumbar puncture. Digital substracted angiography (DSA) was performed soon after arrival to confirm the aneurysmal origin of the hemorrhage and document the presence of VS. Patients were divided in three groups accordingly to delay between SAH and surgery: Group 1: 0 to 2 days; Group 2: 3 to 12 days and Group 3: more than 12 days. Ten patients with VS on initial angiography were excluded because they reported a history suggestive of recent prior bleeding.

\section{Initial management}

Patients were admitted to the intensive care unit for close monitoring of neurological and hemodynamic status. Their clinical state was assessed according to the grading system of Hunt and Hess $(\mathrm{H} \& \mathrm{H})$. A good clinical grade was considered for $\mathrm{H} \& \mathrm{H}$ grades $1-2$, an intermediate clinical grade for $\mathrm{H} \& \mathrm{H}$ grade 3 and a poor clinical grade for $\mathrm{H} \& \mathrm{H}$ grades $4-5$. Before cerebral angiography, normovolemia was maintained. The systolic arterial pressure was kept between 100-160 mmHg. No hypotensive episode occurred pre-operatively. When required a ventriculostomy was inserted.

\section{Radiological assessment of VS}

Complete four-vessel digital substracted angiography with antero-posterior, lateral and oblique views was performed soon after arrival. At our center, all angiographs are analyzed separately by the endovascular and neurosurgical team. Angiographic VS was diagnosed by both teams who followed the same evaluation protocol for evaluation of vessel narrowing. The consensus was noted in the patients' charts. On the initial angiography, the narrowed segment was assessed by comparing it to its proximal and distal vessel component. The spastic segment was also evaluated in relation to the intracranial extradural internal carotid artery diameter on both sides. Angiographic VS was characterized in terms of vessel narrowing by less than $50 \%$ or by $50 \%$ or more, an established criterion used in many other studies. ${ }^{10,11}$ Angiographic VS was also described in terms of distribution - whether VS involved single or multiple arteries. Pre-operative angiographies were compared to post-operative angiographies to evaluate the progression of
VS and exclude normal hypoplastic vessels and arteriosclerotic changes. We qualified post-operative angiographic VS as worsened if vessel narrowing passed from less than $50 \%$ narrowing to $50 \%$ or more and/or if VS increased its distribution from a single to multiple vessels. Decreased angiographic VS was defined as vessel narrowing passing from $50 \%$ or greater to less than $50 \%$ and/or if VS restrained its distribution from multiple vessels to a single artery.

\section{Assessment of symptomatic VS and cerebral infarction}

Symptomatic VS was defined as the onset of a decreased level of consciousness and/or focal deficit occurring after SAH in the presence of angiographic VS without confounding factors. ${ }^{12}$ Symptomatic VS, presenting pre-operatively or postoperatively, was confirmed by cerebral angiography which served diagnostic and therapeutic goals.

Cerebral infarction related to VS was defined as a persistent hypodensity on CT scan occurring in the corresponding vasospastic territory. When cerebral infarction appeared on postoperative CT scan, angiography was done to rule-out postoperative vessel occlusion.

\section{Surgical management}

Patients with newly diagnosed aneurysmal SAH were treated with a policy of early surgery, within 48 hours of their admission, regardless of the time elapsed since $\mathrm{SAH}$ and the presence of angiographic or symptomatic VS. Surgery was performed more than 48 hours after admission if supplementary imaging was required as for patients of Group 3. Maximum duration of temporary clip usage was assessed by reviewing operative reports. Systolic arterial blood pressure was maintained between $100-120 \mathrm{mmHg}$ during surgery, even at the time of temporary clipping of cerebral vessels. An hypotensive episode was avoided throughout surgery. However, systolic arterial pressure decreased below $90 \mathrm{mmHg}$ for more than five minutes in three patients, of which none developed post-operative symptomatic vasospasm or cerebral infarct. Thorough, gentle irrigation of basal cisterns was routinely done to remove the subarachnoid clot and papaverine was topically applied on the manipulated arteries.

\section{Post-operative management}

Post-operatively all patients were admitted to the intensive care unit for close monitoring of neurologic and hemodynamic status. Nimodipine was administered orally $60 \mathrm{mg}$ every four hours in the post-operative period, except in one patient who received intravenous nicardipine. All patients had a central line installed after the induction by the anesthesiologist. However a pulmonary-artery catheter was not systematically used at our center since the routine use of this catheter in non-cardiac surgery is controversial. ${ }^{13}$ Also, its usefulness in the context of vasospasm as a guide for maximum hydratation, as suggested by Corsten and colleagues, must be validated by further studies. ${ }^{14,15}$ Hypervolemic hypertension was induced with a combination of crystalloids and colloids such as human albumin solution. The hematocrit level was measured at admission and daily throughout hospitalization. Since the optimal hematocrit level in ischemia has not been established, ${ }^{16}$ the absolute hematocrit 
Table 1: Population characteristics

\begin{tabular}{|cccc|}
\hline Sex & Male: 14 & Female: 26 \\
Age & Mean: 48.6 & Range: 16 to 75 & \\
\hline $\begin{array}{c}\text { Hunt \& Hess } \\
\text { Grade }\end{array}$ & $\mathbf{1}(\mathrm{n}=12)$ & $\mathbf{2}(\mathrm{n}=25)$ & $\mathbf{3}(\mathrm{n}=3)$ \\
\hline $\mathbf{1}(\mathrm{n}=16)$ & 0 & 13 & 1 \\
$\mathbf{2}(\mathrm{n}=14)$ & 4 & 6 & 1 \\
$\mathbf{3}(\mathrm{n}=13)$ & 3 & 6 & 1 \\
$\mathbf{4}(\mathrm{n}=6)$ & 4 & 0 & 0 \\
$\mathbf{5}(\mathrm{n}=1)$ & 1 & 0 & 0 \\
\hline
\end{tabular}

level did not guide hypervolemic therapy adjustment. The mean hematocrit value at admission was 0.417 , varying between 0.300 and 0.510 and the lowest level measured during hospitalization was 0.274 , varying between 0.200 and 0.385 . Pressor agents such as neosynephrine and dopamine, were used in four patients when systolic arterial pressure fell below $120 \mathrm{mmHg}$ in the presence of an optimal hyperdynamic therapy. No hypotensive episode occurred in the post-operative setting. Angioplasty was performed in two patients of Group 2 for severe symptomatic vasospasm manifest in the post-operative period.

\section{Outcome assessment}

The functional outcome was assessed three months after surgery using the Glasgow Outcome Scale. The information was collected through chart revision. Good recovery and mild disability were considered as a favorable outcome.

\section{Statistical analysis}

The frequency of symptomatic VS and cerebral infarct in the three surgical groups was analyzed using the Fisher exact test. Separate Fisher exact tests were performed for pre-operative and post-operative events. In addition to testing the differences between the three groups, we also tested the difference between Groups 1 and 2, i.e. the two largest groups. The same approach was used to compare the frequency of favorable functional outcome. Significance level was defined as $\mathrm{p} \leq 0.05$.

\section{Results}

During the study period, 894 consecutive patients were surgically treated for an aneurysmal SAH. Angiographic VS on admission was documented in 50 patients of which ten were excluded because of a history suggestive of a recent prior bleeding. Therefore, 40 patients were retained for the present study. Patients were operated two days or less after SAH onset in $12 / 40(30 \%)$, between 3 to 12 days in 25/40 (62.5\%) and after more than 13 days in $3 / 40(7.5 \%)$. Patient characteristics are presented in Table 1.
Pre-operative symptomatic VS was diagnosed in 10/40 (25\%) of the patients of which two were in Group 1, seven in Group 2, and one in Group 3. Nine of these 10 patients were in good or intermediate clinical grade on admission.

Pre-operative CT showed evidence of SAH in 12/12 (100\%) patients of Group 1; in 21/25 (84\%) patients of group 2; in $1 / 3$ $(33 \%)$ patient of group 3. A focal cerebral brain infarct related to VS was present on admission CT scan in two patients of group 2 .

The time elapsed between initial angiography and aneurysm clipping as well as the description of pre-operative angiographic VS are presented in Table 2. Aneurysm clipping was performed 24 hours or less after initial angiography in 35/40 (87.5\%) patients and 48 hours or less after initial angiography in 39/40 (97.5\%). Pre-operative angiographic VS involved most frequently single vessels in Group 1 and multiple vessels in Groups 2 and 3. Vessel narrowing was less than 50\% in 21/40 patients $(52.5 \%)$ of the studied population. Multiple aneurysms were present in 12/40 (30\%): four presented bilateral aneurysms and eight ipsilateral aneurysms to the ruptured aneurysm. Of these eight patients, more than one aneurysm was clipped in five patients. Distribution of aneurysm responsible for $\mathrm{SAH}$ in regards to location is shown in Table 3. In two cases of multiple aneurysms the exact origin of SAH could not be determined. For these patients both aneurysms were tabulated totaling 42 aneurysms. Aneurysms were small $(\leq 1 \mathrm{~cm})$ in $38 / 40(95 \%)$ patients, intermediate size in $1 / 40(2.5 \%)$, and giant $(\geq 2.5 \mathrm{~cm})$ in $1 / 40(2.5 \%)$.

Temporary clipping was noted in the operative reports of $30 / 40(75 \%)$ patients. The maximum duration of clipping was specified in 15 cases. A favorable outcome was achieved in

Table 2: Description and timing of initial angiography

\begin{tabular}{|c|c|c|c|}
\hline \multicolumn{4}{|c|}{ Description of pre-operative VS } \\
\hline \multirow[t]{2}{*}{ Characteristic } & \multicolumn{3}{|c|}{ Surgical group } \\
\hline & $1(n=12)$ & $2(n=25)$ & $3(n=3)$ \\
\hline \multicolumn{4}{|l|}{ Distribution } \\
\hline Single vessel & 7 & 5 & 0 \\
\hline Multiple vessels & 5 & 20 & 3 \\
\hline \multicolumn{4}{|l|}{ Severity } \\
\hline Less than $50 \%$ narrowing & 8 & 13 & 0 \\
\hline $50 \%$ narrowing or more & 4 & 12 & 3 \\
\hline \multicolumn{4}{|c|}{ Delay (in hours) between initial angiography and aneurysm clipping } \\
\hline$[0,24]$ & 12 & 21 & 2 \\
\hline$] 24,48]$ & 0 & 4 & 0 \\
\hline$] 48, \infty$ & 0 & 0 & 1 \\
\hline
\end{tabular}


Table 3: Location of aneurysms responsible for $\mathrm{SAH}$

\begin{tabular}{|cc|}
\hline Location of aneurysm & No. of aneurysms \\
\hline $\mathrm{ACA}^{1}$ & 2 \\
$\mathrm{AcoA}$ & 15 \\
$\mathrm{PcoA}^{3}$ & 8 \\
$\mathrm{MCA}^{4}$ & 14 \\
$\mathrm{IC}^{5}$ & 2 \\
$\mathrm{VB}^{6}$ & 1 \\
\hline
\end{tabular}

${ }^{1}$ ACA: Anterior cerebral artery, ${ }^{2}$ AcoA: Anterior communicating artery, ${ }^{3}$ PcoA: Posterior communicating artery, ${ }^{4} \mathrm{MCA}$ : Middle cerebral artery, ${ }^{5} \mathrm{IC}$ : Internal carotid artery, ${ }^{6} \mathrm{VB}$ : Vertebro-basilar arteries

$12 / 15(80 \%)$ patients who had temporary clipping for 15 minutes or less.

Post-operative CT scan was performed in 38/40 (95\%) patients. A focal cerebral infarct due to VS was diagnosed in six patients: three of Group 1 and three of Group 2. A post-operative angiography was performed during hospitalization in all patients

Table 4: Description and timing of post-operative angiography

\begin{tabular}{|c|c|c|c|}
\hline \multicolumn{4}{|c|}{ Description of post-operative VS } \\
\hline \multirow[t]{2}{*}{ Characteristic } & \multicolumn{3}{|c|}{ Surgical group ${ }^{1}$} \\
\hline & $1(11)$ & $2(25)$ & $3(3)$ \\
\hline Absence of VS & 1 & 4 & 0 \\
\hline \multicolumn{4}{|l|}{ Distribution } \\
\hline Single vessel & 1 & 5 & 0 \\
\hline Multiple vessels & 9 & 16 & 3 \\
\hline \multicolumn{4}{|l|}{ Severity } \\
\hline Less than $50 \%$ narrowing & 3 & 10 & 2 \\
\hline $50 \%$ narrowing or more & 7 & 11 & 1 \\
\hline \multicolumn{4}{|c|}{ Delay (in days) between initial symptomatology and first post-operative angiography } \\
\hline$[0,2]$ & 1 & 0 & 0 \\
\hline ]2,7] & 6 & 3 & 0 \\
\hline 77,12$]$ & 3 & 15 & 0 \\
\hline$] 12,21]$ & 1 & 6 & 1 \\
\hline ]21, $\infty$ & 0 & 1 & 2 \\
\hline
\end{tabular}

${ }^{1}$ Numbers in parentheses represent patients that underwent a post-operative angiography. except for one of Group 1. The delay between initial symptomatology and first post-operative angiography as well as the description of post-operative angiographic VS are described in Table 4. Initial post-operative angiographies were performed prior to 13 days after SAH in 28/39 (71.8\%) patients. Postoperative angiographic VS was present in $34 / 39(87.2 \%)$ patients. It concerned most frequently multiple vessels in $28 / 34$ $(82.3 \%)$ and consisted most commonly in a narrowing of $50 \%$ or more in $19 / 34$ (55.9\%). In comparison with pre-operative angiographic images, post-operative angiographies revealed that VS had worsened after aneurysmal clipping in 15/34 (44.1\%) patients: seven patients of Group 1 and eight patients of Group 2. Angiographic VS had decreased or reversed post-operatively in 16/34 (47\%) patients: 2 of Group 1, 12 of Group 2 and 2 of Group 3. The other patients had similar pre- and post-operative angiographic VS.

Post-operative symptomatic VS was diagnosed in 12/40 $(30 \%)$ patients: three were in Group 1; seven in Group 2; two in Group 3. Clinical grade on admission was good or intermediate in $10 / 12(83.3 \%)$ of these patients. Post-operative symptomatic VS was also present pre-operatively in $8 / 12(66.7 \%)$ patients. The post-operative angiographies of these patients demontrated increased VS in five patients, similar VS in two patients and diminished VS in one patient. Five patients presented de novo post-operative symptomatic VS, four of which showed increased VS on post-operative angiography that was treated by angioplasty in two cases.

The frequency of symptomatic VS and cerebral infarct due to VS in relation to timing of surgery are presented in Table 5. Of the three patients that developed a cerebral infarct in Group 1, one presented an increase in vessel narrowing and two presented an increase of VS distribution. Of the three patients that developed a cerebral infarct in Group 2, one presented an increase in vessel narrowing in a multiple vessel distribution similar pre- and -post-operatively. The second patient showed a decrease in vessel narrowing involving multiple arteries and the third a similar pattern in terms of vessel diameter and distribution. There are no statistically significant differences between the four groups regarding the proportion of subjects who manifested symptomatic VS ( $\mathrm{p}=0.22$ for Fisher exact test in the pre-operative period and $\mathrm{p}=0.49$ for the post-operative period) or who developed cerebral infarct ( $\mathrm{p}=0.99$ for the preoperative period and $\mathrm{p}=0.66$ for the post-operative period).

Figure 1 illustrates the example of a patient included in the present study. This was a 63-year-old woman with no prior medical history who presented for a persisting headache that had begun six days before. On admission, the patient's vital signs and neurological exam were normal. Initial CT-scan showed no evidence of a SAH nor cerebral infarction. However, the lumbar puncture was positive for SAH. The cerebral angiography revealed the presence of a single aneurysm of the anterior communicating artery as well as the presence of vessel narrowing greater than $50 \%$ on multiple vessels (Figure $1 \mathrm{a}, \mathrm{b}$ ). Within 24 hours of admission, the patient was brought to the operating room (OR) for surgical treatment of the aneurysm. Post-operative CT-scan showed no complications related to the VS and the intra-hospital follow-up angiography revealed complete exclusion of the aneurysm and improvement of the VS 
in comparison to pre-operative period (Figure $1 \mathrm{c}$ ). Three months after surgery, the patient had regained her normal activities.

The functional outcome assessed three months after surgery was favorable in $37 / 40(92.5 \%)$ of patients with aneurysmal $\mathrm{SAH}$ and associated pre-operative angiographic VS, regardless of Hunt and Hess grade at admission. However, a favorable outcome was significantly more likely in patients operated between 3 to 12 days after $\mathrm{SAH}$ than those operated in the first 48 hours following SAH ( $\mathrm{p}=0.03$ ). Table 6 compares the frequency of favorable clinical outcomes for the three groups. For patients with pre-operative symptomatic VS, only $70 \%$ presented a favorable outcome. Of the three patients who evolved towards an unfavorable outcome, the initial effect of SAH was the cause in one patient and VS in the two others. The mortality rate was $4 \%(2 / 50)$. These two patients presented pre-operative clinical VS without cerebral infarct on preoperative CT scan. They underwent surgery within 48 hours of the hemorrhagic event. Both deaths were related to severe postoperative VS.

\section{Table 5: Radiological and clinical findings due to vasospasm in relation to timing of surgery}

\begin{tabular}{|lcccc|}
\cline { 2 - 5 } & \multicolumn{5}{c}{ Surgical group } & Total \\
\hline PRE-OPERATIVE PERIOD & $\mathbf{1}$ & $\mathbf{2}$ & $\mathbf{3}$ & 40 \\
\hline Angiographic vasospasm & 12 & 25 & 3 & 10 \\
Symptomatic vasospasm & 2 & 7 & 1 & 2 \\
Cerebral infarct & 0 & 2 & 0 & 5 \\
\hline POST-OPERATIVE PERIOD & & & & 34 \\
\hline No vasospasm on angiography & 1 & 4 & 0 & 12 \\
\hline Angiographic vasospasm & 10 & 21 & 3 & 6 \\
Symptomatic vasospasm & 3 & 7 & 2 & \\
Cerebral infarct & 3 & 3 & 0 & \\
\hline
\end{tabular}

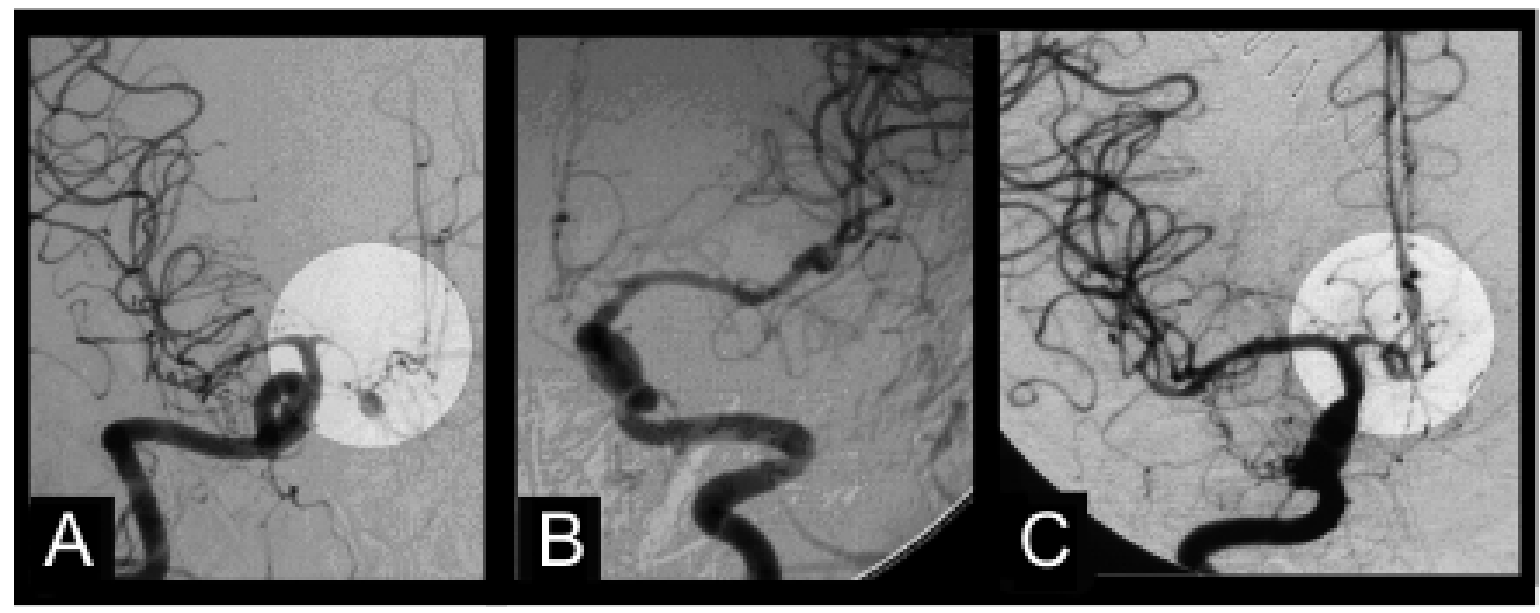

Figure 1: A 63 year-old woman presented for a persisting headache that began 6 days ago. A\&B) Initial angiography with an anterior communicating aneurysm and vessel narrowing greater than $50 \%$ on multiple vessels. C) Post-operative angiography 10 days after initial hemorrhage with complete exclusion of the aneurysm and improvement of VS.

Table 6: Functional outcome in relation to surgical group

\begin{tabular}{|ccc|}
\hline $\begin{array}{c}\text { Surgical } \\
\text { Group }\end{array}$ & Favorable & Unfavorable \\
\hline $\mathbf{1}$ & 9 & 3 \\
$\mathbf{2}$ & 25 & 0 \\
$\mathbf{3}$ & 3 & 0 \\
Total & 37 & 3 \\
\hline
\end{tabular}

\section{DISCUSSION}

The optimal timing of surgical treatment for ruptured intracranial aneurysms remains controversial. Recently authors of a meta-analysis on timing of aneurysm surgery suggested that both early and intermediate surgical treatments improved outcomes in all clinical grades. ${ }^{3}$ Many clinicians will agree that most ruptured aneurysms should be treated as early as possible by surgical or endovascular means. The conclusion concerning intermediate surgical treatment might be less widely accepted since most clinicians have the impression of an increased incidence of ischemic complications. Our series does not support this belief. Surgery performed in the presence of angiographic VS can be associated with a good outcome. Patients operated on within 48 hours after $\mathrm{SAH}$ had a favorable outcome in $75 \%$ (9/12); those operated on between the 3rd and 12th day after SAH had a favorable outcome in $100 \%(25 / 25)$ of cases as those did operated more than 12 days after SAH. 
Some series have suggested that delayed cerebral ischemia, post-operative VS, and poorer outcomes occur more frequently in patients operated during the period at risk of VS, regardless of its angiographic documentation. ${ }^{2,7-9,17}$ An hypothesis explaining reported unfavorable results is that surgery, by dissection and manipulation of arteries already irritated by subarachnoid blood, might precipitate or exacerbate arterial narrowing. ${ }^{18-20}$

In an experimental study, Findlay et $\mathrm{al}^{18}$ induced bilateral $\mathrm{SAH}$ in primates. Operative manipulation and temporary clip placement did not result in worsening of the VS documented on follow-up angiography. In our series, temporary clipping in the presence of vasospastic cerebral arteries was not associated with an unfavorable outcome.

In a clinical study Macdonald et $\mathrm{al}^{21}$ measured arterial diameter on angiographies performed before and after aneurysm clipping in 56 patients: 34 were operated on by day three of SAH, 20 between SAH day 4 - 12, and two after SAH day 13. They found that neither surgery itself nor its timing, had an effect on angiographic VS. Qureshi et $\mathrm{al}^{22}$ analyzed 296 consecutive patients diagnosed with SAH of whom 37 had angiographic evidence of early VS at admission. Of these, 24 underwent early surgery which did not aggravate the risk of symptomatic VS and poor outcome. Saito et $\mathrm{al}^{23}$ analyzed 96 consecutive patients that presented with VS during their clinical course. Of the 68 patients with angiographic pre-operative VS, 29 underwent aneurysmal clipping, usually more than a week after documentation of VS. Given the delay between diagnosis of angiographic VS and surgery, the conclusion that subsiding or stable VS was not aggravated by surgery must be critically analyzed. In our series, $39 / 40(97.5 \%)$ patients were operated on 48 hours or less after angiographic documentation of VS and all patients presenting pre-operative clinical VS had a stable neurological deficit prior to surgery. First post-operative angiography was performed prior to 13 days following $\mathrm{SAH}$, therefore including the period most at risk of VS, in 28/39 (71.8\%) patients.

Experimental and clinical evidence support the fact that VS is not aggravated by surgical procedure. Early aneurysm clipping might enable better treatment of existing delayed ischemic neurological deficits and prevent or limit the formation of cerebral infarcts. Solomon et $\mathrm{al}^{8}$ prospectively studied 145 patients admitted within seven days of SAH and operated on within 24 hours of admission. Symptomatic VS and cerebral infarcts due to VS occurred in $16 \%$ and $4 \%$ of patients respectively, operated on the same day or the day after the $\mathrm{SAH}$; $22 \%$ and $10 \%$ of those operated on day 2-3 after SAH; $28 \%$ and $11 \%$ of those operated on between day 4-7 after SAH. Unfavorable outcome due to delayed cerebral ischemia occurred in $2 \%$ of patients operated on the same day or the day after the $\mathrm{SAH}, 3 \%$ of those operated on day 2-3 after SAH, and 3\% of those operated between day 4-7 after $\mathrm{SAH}{ }^{8}$

Chyatte et al $^{1}$ studied 244 patients admitted within 3 days of aneurysmal SAH. Patients operated on within 3 days of SAH presented a statistically significant increase in the post-operative ischemic symptoms balanced by a similar rate of pre-operative complications in patients undergoing delayed surgery. Moreover, the increased incidence of complications due to VS in the early surgical group did not result in statistically significant increase in morbidity as most were reversible. ${ }^{1}$ Surgery seems to have little influence on bad clinical outcome due to VS., ${ }^{1,8}$
Post-operative clinical deterioration and unfavorable functional prognostic might not be due to VS. ${ }^{24}$ Surgical complications, less frequently sought systematically, might be an important contributor of unfavorable outcome. ${ }^{25-29}$ Altered cerebral blood perfusion and dysautoregulation occurring in the acute setting of SAH might also contribute to poorer results. ${ }^{30}$

Experimental and clinical studies have demonstrated that $\mathrm{SAH}$ induces an acute global decrease in cerebral blood flow $(\mathrm{CBF})$ and cerebral metabolic rate of oxygen $\left(\mathrm{CMRO}_{2}\right)^{31-35}$ which are correlated with higher clinical grades. ${ }^{34,36-38}$ Also, cerebral autoregulation is impaired following aneurysmal SAH and during VS. ${ }^{39-41}$ Parenchymal vessels distal to vasospastic arteries might be unable to dilate in response to reduced local perfusion pressure. ${ }^{41}$ However, some studies suggest that surgery improves CBF patterns ${ }^{36,37}$ partly due to better intracranial pressure control. Neuroanesthetic techniques, large opening of the sylvian and basal cisterns, and hematoma drainage contribute to minimizing the need for brain retraction, reducing the occurrence of focal insults in brain tissue rendered sensitive to changes in local pressure due to altered autoregulation. Once the aneurysm is secured, optimal medical management for VS might be securely optimized and might attenuate the effects of dysautoregulation and VS.

The decision to delay aneurysm clipping for patients with an aneurysmal SAH and angiographic VS must weigh the risk of rebleeding during the waiting period and the risk of presenting neurological ischemic deficits related to VS. Early VS, occurring within 48 hours of aneurysmal rupture, is present in approximately $10-13 \%$ of SAH patients. ${ }^{22,42}$ It represents a significant predictor of neurological deterioration and cerebral infarction and of unfavorable outcome. ${ }^{22,42}$ Interestingly, in our series, early angiographic VS (Group 1) was documented in $12 / 40(30 \%)$ patients of which $7 / 12(58.3 \%)$ presented a good or intermediate clinical grade at admission. Although 7/11 (63.6\%) patients of Group 1 presented worsened angiographic VS postoperatively, symptomatic post-operative VS was not significantly more common than in other groups. An unfavorable outcome was found in $25 \%$ of Group 1 . On the other hand, 12/25 (48\%) patients of Group 2, which covers the interval most at risk for VS, showed a decrease in post-operative angiographic VS and symptomatic post-operative VS was not significantly more frequent. All Group 2 patients evolved towards a favorable outcome at three months after SAH.

Early VS is independant of delayed VS which suggests that these phenomena have a different eotiology. It has been shown that early vasospasm is associated with worse neurological grade, thicker SAH on CT-scan, larger aneurysms and intracranial hemorrhage. ${ }^{42}$ Increased intracranial pressure and stretching of intracranial arteries by adjacent parenchymal hematomas, thick subarachnoid clots or the culprit aneurysm itself, may contribute to vessel narrowing seen in the presence of early VS. ${ }^{42}$ These associated conditions might partially explain the worse prognosis of patients of Group 1 in comparison to patients of Group 2, presenting delayed VS. More studies are necessary to elucidate factors contributing to the difference in outcome observed between patients presenting angiographic VS either early after SAH onset or during the period most at risk for VS. ${ }^{22,42}$

There are some limitations to the present study. Although this is a retrospective study as most series analysing aneurysm 
surgery in the period of vasospasm, there was no patient selection. All patients consecutively treated during the study period were included in the study if they answered the inclusion and not the exclusion criteria. The small number of patients is representative of the frequency of angiographic vasospasm prior to surgical treatment in a tertiary neurosurgical center's practice.

A consensus regarding the description of VS is lacking. Scales, spasm indexes, and measurements techniques have been proposed as instruments to standardize the evaluation of VS. However, their use in clinical practice is not widespread and most authors use personalized classifications. To minimize interobserver variability, we used bimodal variables to describe the diameter of spastic vessels and their distribution.

Not only does radiological definition of vasospasm differ between studies but also the definition of clinical vasospasm. The main factor varying between studies is the onset of neurological symptoms anywhere between 3-5 to 12 days. Precise definitions allowed objective assessments of clinical charts by independent observers. In other studies, exclusion of early clinical vasospasm might have clinical significance in conclusions drawn.

Furthermore, an endovascular treatment securing the ruptured aneurysm and dilating vasospastic arteries either mechanically or pharmacologically could be considered a good option for patients with symptomatic VS on admission. Recent studies have shown that the incidence of angiographic and symptomatic vasospasm and the associated overall clinical outcome does not significantly differ between patients treated with craniotomy and clip application and those treated by embolization. ${ }^{43-46}$ However, only case reports and small series have assessed the safety and effectiveness of combined embolization and angioplasty in a single session for the treatment of ruptured aneurysms associated with symptomatic VS. ${ }^{47,48}$ In the light of these data, a prospective analysis of the outcome of patients with aneurysmal SAH presenting angiographic VS prior to aneurysmal treatment, either by surgical or endovascular means, might be warranted.

In summary, aneurysmal surgery, especially between 3-12 days following $\mathrm{SAH}$, in the presence of asymptomatic preoperative angiographic VS can be associated with a good outcome. Early surgery is not contra-indicated and might enable optimal treatment of VS. However, clinical VS on admission, especially within 48 hours after $\mathrm{SAH}$, might be associated with a less favorable outcome.

\section{REFERENCES}

1. Chyatte D, Fode NC, Sundt TM Jr. Early versus late intracranial aneurysm surgery in subarachnoid hemorrhage. J Neurosurg. 1988;69:326-31.

2. Kassell NF, Torner JC, Jane JA, Halley EC Jr, Adams HP. The international cooperative study on the timing of aneurysm surgery. Part 2: surgical results. J Neurosurg. 1990;73:37-47.

3. de Gans K, Nieuwkamp DJ, Rinkel GJ, Algra A. Timing of aneurysm surgery in subarachnoid hemorrhage: a systematic review of the literature. Neurosurgery. 2002;50:336-40.

4. Haley EC Jr, Kassell NF, Torner JC. The international cooperative study on the timing of aneurysm surgery. The North American experience. Stroke. 1992;23:205-14.

5. Ohman J, Heiskanen O. Timing of operation for ruptured supratentorial aneurysms: a prospective randomized study. J Neurosurg. 1989;70:55-60.

6. Heros RC, Morcos JJ. Cerebrovascular surgery: past, present, and future. Neurosurgery. 2000;47:1007-33.
7. Kassell NF, Torner JC, Haley EC Jr, Jane JA, Adams HP, Kongable GL. The international cooperative study on the timing of aneurysm surgery. Part 1: overall management results. J Neurosurg. 1990;73:18-36.

8. Solomon RA, Onesti ST, Klebanoff L. Relationship between the timing of aneurysm surgery and the development of delayed cerebral ischemia. J Neurosurg. 1991;75:56-61.

9. Suzuki J, Onuma T, Yoshimoto T. Results of early operations on cerebral aneurysms. Surg Neurol. 1979;11:407-12.

10. Grandin CB, Cosnard G, Hammer F, Duprez TP, Stoobandt G, Mathurin P. Vasospasm after subarachnoid hemorrhage: diagnosis with MR angiography. Am J Neuroradiol. 2000;21:1611-17.

11. Anderson GB, Ashforth R, Steinke DE, Findlay JM. CT angiography for the detection of cerebral vasospasm in patients with acute subarachnoid hemorrhage. Am J Neuroradiol. 2000;21:1011-15.

12. Kassell NF, Sasaki T, Colohan ART, Nazar G. Cerebral vasospasm following aneurysmal subarachnoid hemorrhage. Stroke. 1985; 16:562-72.

13. Sandham JD, Hull RD, Brant RF, Knox L, Pineo GF, Doig CJ, et al. A randomized, controlled trial of the use of pulmonary-artery catheters in high-risk surgical patients. $\mathrm{N}$ Engl J Med. 2003;348:5-14.

14. Corsten L, Raja A, Guppy K, Roitberg B, Misra M, Alp MS, et al. Contemporary management of subarachnoid hemorrhage and vasospasm: the UIC experience. Surg Neurol. 2001;56:140-48.

15. Sen J, Belli A, Albon H, Morgan L, Petzold A, Kitchen N. Triple-H therapy in the management of aneurysmal subarachnoid haemorrhage. Lancet Neurol. 2003;2:614-21.

16. Hudak ML, Koehler RC, Rosenberg AA, Traystman RJ, Jones MD Jr. Effect of hematocrit on cerebral blood flow. Am J Physiol. 1986;251:63-70.

17. Sano K, Saito I. Timing and indication of surgery for ruptured intracranial aneurysms with regard to cerebral vasospasm. Acta Neurochir (Wien). 1978;4:49-60.

18. Findlay JM, Macdonald RL, Weir BK, Grace MG. Surgical manipulation of primate cerebral arteries in established vasospasm. J Neurosurg. 1991;75:425-32.

19. Flamm ES. Parasurgical treatment of aneurysms. Clin Neurosurg. 1977;24:240-7.

20. Sundt TM Jr. Cerebral vasospasm following subarachnoid hemorrhage: evolution, management, and relationship to timing of surgery. Clin Neurosurg. 1977;24:228-39.

21. Macdonald RL, Wallace MC, Coyne TJ. The effect of surgery on the severity of vasospasm. J Neurosurg. 1994;80:433-9.

22. Qureshi AI, Sung GY, Suri MA, Straw RN, Guterman LR, Hopkins LN. Prognostic value and determinants of ultraearly angiographic vasospasm after aneurysmal subarachnoid hemorrhage. Neurosurgery. 1999; 44:967-73.

23. Saito I, Ueda Y, Sano K. Significance of vasospasm in the treatment of ruptured intracranial aneurysm. J Neurosurg. 1977;47:412-29.

24. Findlay JM, Deagle GM. Causes of morbidity and mortality following intracranial aneurysm rupture. Can J Neurol Sci. 1998;25:209-15.

25. Fridriksson S, Saveland H, Jakobsson KE, Edner G, Zygmunt S, Brandt L, et al. Intraoperative complications in aneurysm surgery: a prospective national study. J Neurosurg. 2002; 96:515-22.

26. Göran E, Kågström E, Wallstedt L. Total overall management and surgical outcome after aneurysmal subarachnoid hemorrhage in a defined population. Br J Neurosurg. 1992;6:409-20.

27. Le Roux PD, Elliot JP, Newell DW, Grady MS, Winn HR. The incidence of surgical complications is similar in good and poor grade patients undergoing repair of ruptured anterior circulation aneurysms: a retrospective review of 355 patients. Neurosurg. 1996;38:887-95.

28. McLaughlin N, Bojanowski MW. Early surgery-related complications after aneurysm clip placement: an analysis of causes and patient outcomes. J Neurosurg. 2004;101:600-6.

29. Proust F, Hannequin D, Langlois O, Freger P, Creissard P. Causes of morbidity and mortality after ruptured aneurysm surgery in a series of 230 patients. The importance of control angiography. Stroke. 1995;9:1553-7. 
30. Wilkins RH. The role of intracranial arterial spasm in the timing of operations for aneurysm. Clin Neurosurg. 1977;24:185-207.

31. Frykholm P, Andersson JL, Langstrom B, Persson L, Enblad P. Haemodynamic and metabolic disturbances in the acute stage of subarachnoid haemorrhage demonstrated by PET. Acta Neurol Scand. 2004;109:25-32.

32. Hayashi T, Suzuki A, Hatazawa J, Kanno I, Shirane R, Yoshimoto T, et al. Cerebral circulation and Metabolism in the acute stage of subarachnoid hemorrhage. J Neurosurg. 2000;93:1014-8.

33. Kawamura S, Sayama I, Yasui N, Uemura K. Sequential changes in cerebral blood flow and metabolism in patients with subarachnoid haemorrhage. Acta Neurochir (Wien). 1992; 114:12-5.

34. Meyer CH, Lowe D, Meyer M, Richardson PL, Neil-Dwyer G. Progressive change in cerebral blood flow during the first three weeks after subarachnoid hemorrhage. Neurosurgery. 1983; 12:58-76.

35. Prunell GF, Mathiesen T, Svendgaard NA. Experimental subarachnoid hemorrhage: cerebral blood flow and brain metabolism during the acute phase in three different models in the rat. Neurosurgery. 2004;54:426-36.

36. Merory J, Thomas DJ, Humphrey PR, DuBoulay GH, Marshall J, Russell RW, et al. Cerebral blood flow after surgery for recent subarachnoid haemorrhage. J Neurol Neurosurg Psychiatry. 1980;43:214-21.

37. Mountz JM, McGillicuddy JE, Wilson MW, Bartold SP, Siegal EM. Pre- and post-operative cerebral blood flow changes in subarachnoid haemorrhage. Acta Neurochir (Wien). 1991; 109:30-3.

38. Rosenstein J, Wang AD, Symon L, Susuki M. Relationship between hemispheric cerebral blood flow, central conduction time, and clinical grade in aneurysmal subarachnoid hemorrhage. J Neurosurg. 1985;62:25-30.

39. Lang EW, Diehl RR, Mehdorn HM. Cerebral autoregulation testing after aneurysmal subarachnoid hemorrhage: the phase relationship between arterial blood pressure and cerebral blood flow velocity. Crit Care Med. 2001;29:158-63.
40. Soehle M, Czosnyka M, Pickard JD, Kirkpatrick PJ. Continuous assessment of cerebral autoregulation in subarachnoid hemorrhage. Anesth Analg. 2004;98:1133-9.

41. Yundt KD, Grubb RL Jr, Diringer MN, Powers WJ. Autoregulatory vasodilation of parenchymal vessels is impaired during cerebral vasospasm. J Cereb Blood Flow Metab. 1998;18:419-24.

42. Baldwin ME, Macdonald RL, Huo D, Novakovic RL, Goldenberg FD, Frank JI, et al. Early vasospasm on admission angiography in patients with aneurysmal subarachnoid hemorrhage is a predictor for in-hospital complications and poor outcome. Stroke. 2004;35:2506-11.

43. Dehdashti AR, Mermillod B, Rufenacht DA, Reverdin A, de Tribolet N. Does treatment modality of intracranial ruptured aneurysms influence the incidence of cerebral vasospasm and clinical outcome? Cerebrovasc Dis. 2004;17:53-60.

44. Goddard AJ, Raju PP, Gholkar A. Does the method of treatment of acutely ruptured intracranial aneurysms influence the incidence and duration of cerebral vasospasm and clinical outcome? J Neurol Neurosurg Psychiatry. 2004;75:868-72.

45. Hoh BL, Topcuoglu MA, Singhal AB, Pryor JC, Rabinov JD, Rordorf GA, et al. Effect of clipping, craniotomy, or intravascular coiling on cerebral vasospasm and patient outcome after aneurysmal subarachnoid hemorrhage. Neurosurgery. 2004;55:779-86.

46. Rabinstein AA, Pichelmann MA, Friedman JA, Piepgras DG, Nichols DA, McIver JI. Symptomatic vasospasm and outcomes following aneurysmal subarachnoid hemorrhage: a comparison between surgical repair and endovascular coil occlusion. J Neurosurg. 2003;98:319-25.

47. Sugiu K, Katsumata A, Ono Y, Tamiya T, Ohmoto T. Angioplasty and coiling of ruptured aneurysm with symptomatic vasospasm: technical case report. Surg Neurol. 2003;59:413-7.

48. Murayama Y, Song JK, Uda K, Gobin YP, Duckwiler GR, Tateshima S. Combined endovascular treatment for both intracranial aneurysm and symptomatic vasospasm. Am J Neuroradiol. 2003;24:133-9. 